\title{
ESTRATÉGIAS DE SOBREVIVÊNCIA EM FAMÍLIAS DE TRABALHADORES RURAIS ${ }^{12}$
}

\author{
Geraldo Romanelli ${ }^{13}$ \\ Neuzeli Maria de Almeida Bezerra
}

\begin{abstract}
RESUMO: O trabalho tem como objetivo estudar famílias de migrantes residentes em dois bairros de Sertãozinho, no estado de São Paulo, que trabalham na lavoura da cana-de-açúcar. Os dados foram coletados por meio de entrevistas com dez famílias, que foram gravadas e transcritas na íntegra e através da observação participante. $O$ trabalho procura mostrar como se dá a adaptação dos'migrantes no meio urbano e as condições de vida de suas famílias. Para isso, examina-se a contribuição do trabalho das esposas, como geradoras de rendimentos e produtoras de serviços domésticos, essenciais para a reprodução social e biológica dos integrantes da unidade doméstica, bem como a importância da rede de relações constituída por parentes e vizinhos que prestam vários tipos de ajuda às famílias.
\end{abstract}

Palavras chave: família - migrantes - trabalhadores rurais - divisão sexual do trabalho - parentesco vizinhança

\section{Surviving strategies in rural family workers.}

\begin{abstract}
The objective of the present investigation was to study families of migrants residing in two neighborhoods of Sertãozinho, in the state of São Paulo, who work in sugar cane fields. Data were collected by interviewing ten families and the interviews were taped and transcribed completely. Also, data were collected by participant observation. The study was

an attempt to show how the migrants adapt to the urban medium and the living conditions of their families. We also examined the contribution of the work of their wives, as generators of income and as producers of domestic services essential for the social and biological reproduction of the members of the domestic unit, as well as the importance of the network of relations consisting of relatives and neighbors that give several types of aid to the families.
\end{abstract}

Key words: family - migrants - rural workers - sexual division of labor - kinship - neighbor relationships

Transformações recentes na sociedade brasileira, decorrentes da crise no processo de modernização econômica, iniciadas nos anos 80 , aumentam a desigualdade social e ampliam os problemas de sobrevivência de famílias da população de baixa renda dos centros urbanos. Essas mudanças no plano econômico, que afetam a estrutura do sistema produtivo, acarretando desemprego, baixos salários e precariedade nas relações de trabalho, são acompanhadas pela demissão do Estado na

\footnotetext{
${ }^{12}$ Pesquisa realizada como o apoio da FAPESP

${ }^{13}$ Endereço para correspondência: Geraldo Romanelli. Depto. de Psicologia e Educação. Faculdade de Filosofia, Ciências e Letras de Ribeirão Preto. Universidade de São Paulo. Avenida Bandeirantes, 3900-CEP 14040-901. Ribeirão Preto-SP. Fone/ fax (16)602-3793. E-mail:geromane@ffclrp.usp.br
}

manutenção de conquistas sociais, o que produz redução e ineficácia dos serviços públicos, como saúde e educação, e dos equipamentos urbanos, que incluem transporte, serviços de água, luz, esgoto.

Como conseqüência, tem-se maior empobrecimento da população brasileira que estimula o processo migratório, seja do campo para a cidade, seja de localidades com parcas possibilidades de emprego para centros economicamente mais dinâmicos. Em especial, as correntes migratórias dirigem-se para áreas onde a presença da indústria e, mais recentemente, da agroindústria leva as famílias pobres a avaliarem esses locais como privilegiados, onde conseguirão trabalho e melhores condições de vida.

$\mathrm{O}$ processo migratório desencadeia a

Paidéia, FFCLRP-USP, Rib. Preto, junho/99. 
necessidade de reformulação no equipamento cultural e nas formas de relacionamento dos migrantes para que possam adaptar-se a uma nova realidade socioeconômica, diversa daquela onde foram socializados e preparados para o trabalho. Por isso, a transferência para áreas urbanas é um empreendimento familiar que tende a seguir trajetórias já percorridas por parentes, amigos ou conterrâneos (Durham, 1973), que oferecem informações a respeito das oportunidades de trabalho. Assim, a migração ocorre a partir da expectativa de contar com apoio de uma rede de relações pessoais, construídas no local de origem e que tem possibilidade de se reproduzir na cidade escolhida pelos migrantes para se estabelecerem, constituindo fonte de amparo para a integração no meio urbano. Essas redes de relações, compostas a partir de vínculos eminentemente personalistas, são o oposto das que predominam em áreas urbanas, nas quais vigoram princípios formais e burocráticos, que criam obstáculos para a adaptação dos migrantes. A principal dificuldade é a obtenção de emprego por pessoas pouco ou nada escolarizadas e que se defrontam com um mercado de trabalho competitivo - organizado segundo modalidades diversas das que imperam no local de origem - que demanda mão-deobra minimamente qualificada para ocupar postos de trabalho, criados e regidos por relações impessoais.

Para enfrentar os problemas de sobrevivência, os migrantes têm utilizado, no âmbito dessas relações interpessoais, algumas estratégias que este trabalho examina, a partir de pesquisa realizada com famílias de trabalhadores da lavoura canavieira de Sertãozinho no estado de São Paulo.

Segundo dados do Cadastro de Informações Sociais de Sertãozinho, em 1998, essa cidade conta com 88.418 habitantes, dos quais $45,43 \%$ é constituído por migrantes de cidades paulistas e de outros estados. Criada no final do século passado, no período da expansão cafeeira, a cidade atrai, nessa fase, grande número de migrantes nacionais, oriundos dos estados de Minas Gerais, Bahia e Pernambuco, e estrangeiros, sobretudo italianos. Devido a vários fatores, a cafeicultura foi sendo substituída pelo cultivo do algodão e da cana-de-açúcar. No presente, a economia da cidade depende basicamente da agroindústria açucareira, que tem grande impulso na década de 70 com a implantação do PROALCOOL, gerando novo surto de crescimento econômico e atraindo novas levas de migrantes nacionais.

A introdução da agroindústria demanda mãode-obra diversificada, desde bóias-frias sem experiência em trabalho urbano e com reduzida escolaridade, até operários qualificados e especialistas para as usinas de processamento da canade-açúcar e para o setor metalúrgico da cidade, responsável pela produção e manutenção de máquinas e equipamentos para a agroindústria.

As relações econômicas implantadas pela agroindústria geram novos postos de trabalho, mas também demandam tecnologias mais avançadas $e$ poupadoras de mão-de-obra, acarretando o desemprego e tornando precárias e instáveis as relações de trabalho de vários segmentos da população. Junta-se a isso, o caráter sazonal da lavoura canavieira, que afeta particularmente o segmento mais pobre e menos qualificado de trabalhadores, composto especialmente por migrantes.

É nessas circunstâncias de trabalho precário e de desemprego que vivem as famílias estudadas e que ocupam dois bairros da periferia de Sertãozinho.

\section{Organização de famílias de migrantes}

Apesar das mudanças na forma de organização familiar, o arranjo doméstico que ainda prevalece na sociedade brasileira é representado pela família nuclear, constituída por marido, esposa e filhos (Oliveira, 1996). No entanto, tem aumentado o número de famílias chefiadas por mulheres, nas quais o grupo doméstico permanente é composto por uma mulher e seus filhos, que podem ser fruto de uma ou várias uniões. Nessas famílias, a presença de um marido ou companheiro tende a ser ocasional e intermitente, o que cria grandes dificuldades para a sobrevivência. Outra forma de ordenação doméstica, é a família ampliada, nas quais, ao lado do casal e dos filhos, agregam-se parentes do marido e/ou da esposa.

A família é constituída pelo casamento civil - e opcionalmente pelo religioso - ou pela união consensual, sem vínculo legal, arranjo que tem aumentado em todas as camadas da população brasileira (Oliveira, 1996). Ela envolve um conjunto 
de relações entre os integrantes das quais a mais relevante é a de aliança ou afinidade, criada com o cônjuge, a de descendência - com ascendentes e descendentes - e a de consangüinidade, com irmãos (Lévi-Strauss, 1966; Durham, 1983).

$O$ vínculo conjugal cria uma relação afetiva e de solidariedade entre marido e esposa que pode entrar em conflito com a solidariedade devida aos parentes consangüíneos de cada um dos cônjuges. Desse modo, relações de aliança estão, inevitavelmente, em estado de tensão latente com o princípio de consangüinidade e os conflitos daí decorrentes manifestam-se em situações de crise.

Qualquer que seja a forma de organização e a classe social a que pertença, a família configura-se como unidade de reprodução social responsável pelos cuidados e pela socialização dos imaturos. Para realizar a reprodução social, a unidade doméstica é, necessariamente, grupo de cooperação econômica e de consumo coletivo de bens materiais e simbólicos, o que coloca, em primeiro plano, a dimensão coletiva da vida doméstica (Durham, 1983). É como grupo que a família reúne rendimentos individualizados de seus integrantes e organiza o consumo, como documentam vários estudos (Bilac, 1978; Durham, 1980; Macedo, 1979; Fausto Neto, 1982; Zaluar, 1985; Romanelli, 1986).

Mas a família configura-se também como espaço da vida privada, onde emoções e sentimentos podem ser expressos mais livremente do que na esfera pública, o que resulta tanto em amparo, proteção, solidariedade, quanto em tensões, disputas e conflitos. Ainda como esfera privada, a família é local privilegiado no qual os integrantes trocam informações e experiências e organizam a compreensão da sociedade, traçam projetos para o futuro e pensam o presente, comparando-o com o passado.

No entanto, a dimensão coletiva da vida doméstica coloca a realização dos interesses individuais de seus componentes em confronto. Atualmente, alguns estudos (Velho, 1986; Salem, 1989; Vaitsman, 1994; Romanelli, 1995) constatam o aumento do individualismo no interior da família, que se contrapõe ao familismo, que é a preservação do interesse grupal da unidade doméstica. $O$ individualismo manifesta-se no desejo de consumo de bens materiais e na busca de autonomia dos integrantes, em especial esposas e filhos, o que entra em conflito com a autoridade do marido/pai. $\mathrm{O}$ individualismo está presente em famílias de todas as classes sociais, embora assuma características específicas ém unidades domésticas da população de baixa renda.

A família é criada pelo casamento, mas também é estruturada pela divisão sexual do trabalho, que delimita as funções de homens e mulheres, e está associada à construção da identidade de cada um dos sexos. Na sociedade brasileira, a divisão sexual do trabalho fundava-se em moldes tradicionais e em princípios bastante rígidos que atribuíam à mulher as atribuições de esposa e mãe, confinando-a à execução de tarefas da esfera privada. Isso não impedia o trabalho feminino extradoméstico, mas, preferencialmente, direcionava-o para a realização de atividades como as de professora, de enfermeira, de assistente social, de empregada doméstica e outras associadas ao universo familiar. Quanto aos homens, os princípios da divisão sexual do trabalho excluíamnos da realização dos afazeres domésticos, considerados como de responsabilidade exclusiva das mulheres, atribuindo a eles o engajamento no universo público do mercado de trabalho. Como consequêencia dessa rígida dicotomia, cabia aos homens, em particular aos casados, a responsabilidade de provedor financeiro das necessidades domésticas e o exercício da autoridade e do poder, que ele manipulava enquanto chefe da família.

Desse modo, a família era estruturada de modo hierarquizado com relações de autoridade e de poder fundadas na dominância masculina. Nessa forma de ordenação doméstica, o familismo era mantido pela autoridade do chefe da família que impunha sua vontade como se fosse a vontade geral da família. Obviamente, a dominação masculina não excluía certa participação da esposa e dos filhos na tomada de decisões de problemas familiares, mas essa participação ficava subordinada aos imperativos da vontade do marido/pai.

Contudo, mudanças recentes, que surgem com mais vigor na década de 60 , alteram os pressupostos onde se assentava a divisão sexual do trabalho. Dentre essas modificações, a ampliação da mão-de-obra feminina em atividades remuneradas, no setor formal ou informal do mercado de trabalho, 
acarretou mudanças na divisão sexual do trabalho, afetando a posição das mulheres, sobretudo das casadas, bem como dos homens, na estrutura da família.

Nas famílias de baixa renda, contudo, o padrão tradicional de autoridade e de hierarquia no âmbito doméstico sofreu poucas alterações. A estrutura dessas famílias é ainda pautada pela dominância do marido que, apesar de ver reduzida sua autoridade, continua a ser a figura dominante no núcleo doméstico.

Nessas famílias há certa tendência a manter a esposa no âmbito da esfera privada, o que não é explicado apenas pela restrição dos maridos ao trabalho extradoméstico das esposas, mas deve ser relacionado ao que Zaluar (1985) denomina de ética do provedor. De acordo com essa ética, que não é exclusiva dos homens de baixa renda da população brasileira, mas é também documentada por estudo sobre operários franceses (Schwartz, 1990), cabe ao marido a responsabilidade pela manutenção do grupo doméstico. Tal postura é condizente com os princípios tradicionais da divisão sexual do trabalho que não são totalmente anulados, seja na prática, seja no universo das representações.

A restrição masculina ao trabalho da esposa - mas não ao das filhas - não deve ser correlacionada apenas à submissão feminina diante das imposições do marido ou à falta de vontade das mulheres de assumir qualquer atividade profissional. Há também a crença masculina e feminina na dignidade do trabalhador que sustenta a família e o apreço que as mulheres têm pelo fato de o marido ser o provedor principal, fatos que não podem ser vistos como simples apego a valores tradicionais ultrapassados, mas representam uma forma de repudiar a degradação salarial e social. A recusa do trabalho extradoméstico da esposa, por parte dela e/ou do marido, significa a valorização de um tipo de vida familiar em que a primeira não tem dupla jornada de trabalho e onde marido e filhos podem contar com tempo para o descanso e o lazer, com o preparo da alimentação e com outros serviços femininos, que asseguram um determinado padrão de qualidade de vida da família como um todo.

Ademais, as mulheres casadas da população de baixa renda encontram escassas oportunidades de participar do mercado de trabalho, devido ao grau de escolaridade, de modo geral, reduzido, o que limita as oportunidades de emprego e faz com que os salários sejam bastante baixos. Os empregos mais acessíveis são aqueles relacionados ao desempenho de afazeres realizados no âmbito privado, como os de empregada doméstica, diarista, faxineira, lavadeira, passadeira. Na maior parte dos casos, tais empregos não oferecem vínculo empregatício formal, o que impede o gozo de direitos trabalhistas, como férias remuneradas, $13^{\circ}$ salário, aposentadoria, assistência médica, etc, ampliando ainda mais as carências vividas por essas famílias. Certamente, muitas mulheres com escolaridade reduzida conseguem trabalho com vínculo formal, seja no setor industrial, como operárias ou em atividades que demandam pouca qualificação, seja no setor de serviços, como balconistas, manicuras, cabeleireiras, faxineiras ou ainda, no setor primário da economia, como é o caso das bóias-frias. No entanto, esses postos de trabalho oferecem baixa remuneração e reduzidas possibilidades de ascensão ou de aumento do salário.

Assim, no interior do sistema produtivo ocorre uma redefinição da divisão sexual do trabalho, já que há relativa igualdade de direitos, pois homens e mulheres são nivelados e igualados enquanto vendedores de força de trabalho anônima e assexuada. No entanto, se as mulheres têm os mesmos deveres, não tem os mesmos direitos, pois seus salários são, geralmente, inferiores aos dos homens.

Já na esfera privada, a divisão sexual do trabalho tende a seguir os moldes tradicionais, cabendo à esposa - ou às filhas - a execução dos afazeres domésticos. Nesse âmbito, coloca-se a imensa importância da produção de valores de uso, fundamentais para a reprodução social da família como um todo. O consumo doméstico é assegurado não apenas pelo rendimento dos integrantes da família, mas por valores de uso produzidos em sua quase totalidade pelas mulheres, que incluem a transformação - e também o conserto - de mercadorias, que resultam em atividades como preparar alimentos, lavar e passar roupa, limpar a casa, além dos cuidados com filhos, idosos, doentes (Durham, 1980). Com menor intensidade, os homens da população pobre também produzem valores de uso como efetuar limpeza de quintal, fazer consertos elétricos, hidráulicos e outros tipos de reparo na moradia, mas, sobretudo, a grande contribuição 
masculina é a construção da casa própria.

Mas a reprodução social da família está também vinculada às diferentes fases do seu ciclo de desenvolvimento, denominadas de constituição, maturação e velhice (Montali, 1990). Esses estágios envolvem a trajetória de marido e esposa no mercado de trabalho, o nascimento dos filhos, a etapa em que se tornam independentes e o momento em que deixam de ser apenas consumidores e tornam-se produtores de rendimentos

Nas famílias de baixa renda, a contribuição financeira dos filhos para o consumo doméstico é extremamente importante e eles começam a trabalhar precocemente, inclusive executando atividades diversas no setor informal do mercado de trabalho antes de 14 anos, idade estabelecida por lei para o início das atividades produtivas (Fausto Neto, 1982; Romanelli, 1997).

Desse modo, além da contribuição financeira da esposa há a dos filhos, o que acarreta mudanças nas relações entre marido e esposa e entre pais e filhos, pois o marido deixa de ser o principal provedor da família o que mina sua autoridade (Romanelli, 1995)

Ainda assim, as dificuldades financeiras persistem e uma estratégia fundamental para enfrentálas é o auxílio de parentes e vizinhos. Pesquisas sobre essas famílias mostram que elas estão integradas em redes de ajuda mútua - fato também documentado em estudos realizados com unidades domésticas na França (Déchaux, 1990; Pitrou, 1992) - organizadas e mantidas principalmente pelas esposas. A mediação delas cria uma forte relação de solidariedade entre parentes consangüíneos, vínculo importante quando ocorrem conflitos conjugais e elas solicitam a ajuda dos irmãos (Fonseca, 1987). Quando esses conflitos ocorrem, o vínculo entre consangüíneos torna-se mais forte do que a relação de aliança entre marido e esposa.

A integração das famílias nas redes horizontais de troca de favores com parentes e vizinhos cria intercâmbio de serviços, que constitui uma estratégia para minimizar os gastos dessas unidades domésticas.

\section{Método}

Participaram da pesquisa dez famílias de migrantes rurais residentes em dois bairros de Sertãozinho, Alvorada e Jardim Paraíso I. Esses bairros foram escolhidos por estarem localizados na periferia da cidade, onde se concentram os migrantes que trabalham na lavoura da cana-de-açúcar.

A amostra é composta por 18 sujeitos, sendo dez esposas e oito maridos, já que há duas famílias chefiadas por mulheres, portanto, sem marido/ companheiro. Devido à grande variabilidade nos arranjos domésticos, a amostra foi constituída por quatro famílias nucleares, quatro ampliadas e duas chefiadas por mulheres.

\section{Procedimento}

Durante os meses de junho a setembro de 1996, foi feito um levantamento de dados secundários envolvendo informações históricas e econômicas sobre Sertãozinho e sobre as condições dos bairros onde residem as famílias e foi aplicado um pré-teste para avaliar a adequação do roteiro de entrevista. Em seguida, procedeu-se à realização das entrevistas, orientadas por um roteiro semi-estruturado, gravadas e transcritas na íntegra, e que tiveram a duração média de uma hora e meia. Cada cônjuge foi entrevistado separadamente, tendo sido esclarecido que permaneceria no anonimato, para assegurar a privacidade. Por isso, os nomes que constam do trabalho são fictícios. Além das 18 entrevistas com os sujeitos das famílias selecionadas, foram efetuadas outras duas com líderes do bairro.

De janeiro a março de 1997, período da entressafra, foram entrevistados os componentes de seis famílias. Na época da safra, de maio a julho do mesmo ano, foram entrevistados os integrantes das quatro famílias restantes.

A realização das entrevistas em épocas distintas permitiu conhecer as condições de vida dessas famílias tanto no período em que há maiores possibilidades de emprego, quanto na fase em que o desemprego aumenta, agravando as condições de sobrevivência.

Outras informações foram obtidas pela prática da observação participante, realizada através de constantes visitas ao bairro, registradas em um diário de campo. 


\section{Resultados}

Dos 18 sujeitos da pesquisa, cinco homens e sete mulheres são migrantes do estado de Minas Gerais, um homem e sua esposa vieram da Bahia, uma mulher é proveniente de Pernambuco, um homem é originário de Batatais, outro de Altinópolis e uma mulher é de Ribeirão Preto, cidades próximas de Sertãozinho. Todos são filhos de trabalhadores rurais e suas primeiras experiências com trabalho foram em atividades agrícolas. A migração foi motivada pela dificuldade de sobrevivência no meio rural e pela busca de melhores empregos e de condições de vida mais favoráveis no meio urbano.

No início, a convivência na cidade foi difícil devido à necessidade de adaptação aos padrões de conduta da realidade urbana, que acarreta o abandono de elementos culturais incorporados durante a socialização primária no campo. Para enfrentar esses obstáculos e conseguir emprego ou moradia quando chegaram à cidade, as famílias migrantes contaram, inicialmente, com o apoio de amigos e parentes de suas localidades de origem.

Os dois bairros onde residem as famílias têm ruas asfaltadas e dispõem de serviços de água, energia elétrica, esgoto e equipamentos de lazer, como quadras de esporte onde os homens disputam partidas de futebol, geralmente nos fins de semana e em feriados. Há também um grande número de bares, freqüentados por homens à tarde, quando chegam do trabalho e nos finais de semana. Já as mulheres encontram-se nas portas das casas nos fins de tarde, conversando com vizinhos e parentes.

As ruas constituem espaço de convivência e sociabilidade e as famílias mantêm uma rede de relações de vizinhança bastante intensa, trocando informações e confidências, o que tanto reforça vínculos de solidariedade, quanto contribui para o surgimento de conflitos. Além das mulheres e das crianças, os homens são presença marcante nas ruas e nos bares, o que pode ser explicado, ao menos em parte, pelo alto índice de desemprego no período de entressafra, o que, segundo os entrevistados, gera aumento da violência. Durante o trabalho de campo, alguns moradores mostraram a região mais perigosa dos bairros, na qual se situa o tráfico de drogas e onde há maior registro de violência. Apontaram também placas de trâñsito com marcas de tiiros, devido à disputa entre traficantes de drogas.

Os integrantes das familias ampliadas e das chefiadas por mulheres consideram essa forma de arranjo como algo momentâneo e, em seus projetos, vislumbram outro tipo de ordenação doméstica. As mulheres chefes de família desejam uma união estável com um companheiro que, além de parceiro afetivo-sexual, seja também colaborador nas despesas domésticas. Esposas e maridos vivendo em famílias ampliadas, aspiram separar-se dos parentes com os quais vivem, para ter moradia independente e a privacidade que não desfrutam.

A origem rural é, em parte, responsável pela baixa escolaridade dos migrantes, pois dois homens e quatro mulheres são analfabetos e seis homens e seis mulheres não concluíram o ensino fundamental. À reduzida escolaridade - e como consequiência dela - alia-se a ausência de qualificação necessária para conseguir trabalhos melhor remunerados.

$O$ rendimento de seis maridos que trabalham na lavoura canavieira situa-se entre um e quatro salários mínimos, enquanto outros dois, que são motoristas em uma usina de açúcar, ganham sete salários mínimos. Esses valores, bem como os auferidos pelas esposas, referem-se ao período da safra, quando contam com atividade regular. $\mathrm{Na}$ entressafra, os ganhos decaem e as famílias enfrentam maiores dificuldades.

Das dez esposas, seis exercem alguma atividade remunerada e ganham entre um e quatro salários mínimos, exceto uma delas que é faxineira em uma residência e recebe como pagamento uma cesta básica que, convertida em moeda, não atinge um salário mínimo. Além disso, na época da entressafra, ela ajuda o marido, capinando quintais de casas particulares. Das outras cinco, três trabalham no corte da cana, uma é manicura e outra é empregada doméstica na parte da manhã, vendedora ambulante de roupas no período da tarde e, nos fins de semana, cabeleireira na própria casa.

Considerando-se o rendimento familiar em salários inínimos, cinco famílias atingem quatro; uma recebe cinco; duas ganham seis, uma alcança sete e a última chega a onze. Os rendimentos acima de cinco salários mínimos são de três famílias ampliadas, nas quais, além do marido, irmãos, sobrinhos ou sogra contribuem com seus salários ou aposentadcria, sendo que, em uma das famílias, o 
marido, como foi dito, é motorista e tem salário mais elevado do que os demais trabalhadores. Outro caso de ganho mais alto é de uma família nuclear, na qual o marido também é motorista. Todavia, deve-se levar em conta que os rendimentos mais elevados das famílias ampliadas devem prover o consumo de maior número de pessoas, o que indica as dificuldades financeiras dessas unidades. O mesmo ocorre com a família nuclear citada acima, pois o casal tem três filhos menores, que não trabalham, e o marido paga pensão à ex-esposa com quem tem seis filhos, dos quais um tem 11 anos.

Ademais, se consideramos as cinco famílias mais pobres, constata-se que três delas são compostas por marido e esposa com menos de 30 anos, cujos filhos têm idade inferior a 12 anos e ainda não exercem nenhuma atividade remunerada. As outras duas famílias nessas condições são chefiadas por mulheres. Esses dados coincidem com os de outras pesquisas que constatam que as famílias que vivem mais precariamente estão na fase de constituição com filhos que não produzem rendimentos, ou então são famílias chefiadas por mulheres, que não contam com os proventos do marido/companheiro.

Apesar da precariedade da situação financeira, tem-se a impressão de que não há miséria total nos dois bairros. A grande maioria das casas é de alvenaria, havendo poucas moradias construídas com materiais provisórios. No entanto, a maioria delas encontra-se inacabada, às vezes sem piso ou sem reboco nas paredes.

Sete famílias conseguiram construir casa própria, na maior parte dos casos, com recursos financeiros provenientes da venda de terrenos ou pequenas propriedades que possuíam no local de origem. Uma prática comum é a compra de um terreno por uma família de migrantes, onde os filhos constroem casas à medida que văo se casando. É comum encontrar-se várias habitações em um mesmo terreno ocupadas por parentes consangüíneos, geralmente da mãe, o que cria uma forte integração, dependência e possibilidade de auxílio entre as famílias, mas que também contribui para gerar tensões e conflitos. A construção da moradia é tarefa coletiva, realizada em regime de mutirão, e que conta com a colaboração dos componentes da família, de parentes e de vizinhos e é realizada geralmente nos finais de semana.
A tendência marcante é de construção da moradia próxima à casa da mãe, às vezes no mesmo terreno onde ela reside, o que pode ser aproximado do princípio de uxorilocalidade, que consiste no fato de os filhos, em especial as filhas, agregaram-se em torno da figura materna, o que é documentado em alguns trabalhos (Abreu Filho, 1980; Fonseca, 1987; Agier, 1990).

O trabalho do corte da cana é penoso e desumano, pois expõe o trabalhador a intempéries. Além disso, a forma e as regras do corte da cana geram rendimentos desiguais, se se considera que o pagamento é feito pela produtividade. Do ponto de vista da capacidade física, homens jovens tendem a cortar mais cana e, conseqüentemente, a ganhar mais do que mulheres, crianças, adolescentes e idosos.

Além do trabalho na lavoura, as mulheres, particularmente as esposas, enfrentam uma sobrecarga de atividades, pois cabe a elas acordar mais cedo, cerca de quatro horas da manhã - para preparar o almoço a ser levado para o trabalho e que será consumido como bóia-fria - e dormir mais tarde, após a realização de outras tarefas domésticas necessárias à reprodução da familia.

Mas o que se observa, principalmente, é que essas famílias continuam a sofrer com o desemprego na época da entressafra, quando as dificuldades financeiras aumentam. Nesse período, são efetuados trabalhos eventuais, que podem durar um dia ou uma semana e que são ligados a atividades agrícolas, como colheita de café, laranja, amendoim, ou a bicos na construção civil, que demandam pouca qualificação da força de trabalho.

Apesar de todas as dificuldades enfrentadas para assegurar a sobrevivência, os migrantes são unânimes em declarar que a vida na cidade melhorou. Essa percepção está associada ao fato de poderem dispor de serviços públicos de saúde e educação que, embora precários, não eram acessíveis no meio rural. Acima de tudo, a escola é pensada como instituição relevante para que os filhos não tenham que enfrentar as dificuldades que eles vivem hoje por não terem tido acesso ao ensino fundamental. Assim, a escolarização dos filhos é avaliada como algo que pode dar condições para que eles possam estar mais preparados para ingressar no mercado de trabalho e, consequientemente, ter empregos e salários melhores. Nessa representação, a família é pensada 
como grupo coletivo, regido pelo princípio do familismo, pois o sucesso de um filho, ou mais filhos, pode repercutir sobre o conjunto da unidade doméstica.

\section{Discussão}

Como os resultados indicam, os papéis de marido e de esposa são bem definidos, cabendo a ela o desempenho das atividades domésticas, os cuidados com os filhos e a socialização destes. Ao marido cabe o papel de provedor responsável pelo sustento da família, mesmo quando seu salário é insuficiente para cobrir as despesas. Essa posição tradicional de autoridade do marido como chefe da família corresponde à ética do provedor e confere a ele posição dominante na família.

Mas tal postura também é partilhada pelas esposas, como se observa na fala de uma delas:

$O$ homem não deixa faltar nada dentro de casa, né? E a mulher deve fazer o serviço de casa, armoço, cuidar do menino... Porque serviço, se for pensar bem, é mais pro homem, principalmente na lavoura. Homem ajuda, mas o dever da casa tem que ser dela.

Apesar de os maridos entrevistados não serem os únicos provedores, pois a contribuição das esposas como produtoras de valores de uso e/ou de rendimentos é essencial para as despesas domésticas, eles tendem a desqualificar essa contribuição, avaliando-a como pouco significativa para assegurar a sobrevivência da família.

No entanto, também as esposas endossam essa representação masculina considerando sua participação para assegurar o consumo doméstico como ajuda secundária, como se apreende na fala de uma delas, que conjuga as atividades de empregada doméstica, cabeleireira e vendedora ambulante e que é bastante ilustrativa do modo como as próprias mulheres contribuem para a manutenção da autoridade inasculina:

A mulher deve trabalhar para ajudar o homem, mas ele deve assumir tudo mesmo... Eu, por exemplo, eu me preocupo com os meus filhos, eu tô sempre, o tempo todo, tentando ajudar ele... Então, o homem tem que pegar esta parte. Só que nem todos fazem isso, por isso que eu acho que esta parte tem de ser do homem.

Nesse quadro de referências, a masculinidade é definida a partir da esfera pública, à medida que os homens devem participar do mercado de trabalho, para cumprir sua função de provedor, enquanto a feminilidade é caracterizada pela relação de apego e de cuidado com os outros. Como consequiência, o trabalho - em oposição ao ócio - define as qualidades do homem e do marido ideal, enquanto as mulheres devem ser responsáveis pela manutenção das relações no interior da família e dos vínculos com os parentes. Por isso, as mulheres, sobretudo as esposas, são as mediadoras, encarregadas do trabalho emocional, voltado para a produção e transformação de pessoas (McMahon, 1993, p.6)

Parentes e vizinhos são extremamente importantes para suprir carências diversas das famílias de migrantes. Todas as famílias estudadas têm parentes no bairro ou em bairros próximos que, junto com vizinhos, formam um grupo de convivência relevante pela afetividade que aí se manifesta, bem como por criar uma teia de relações que propicia a prática da ajuda mútua. Esse apoio, moral ou material, é essencial para os migrantes rurais enfrentarem a dificuldade de sobrevivência no meio urbano, onde a solidariedade tende a ser suplantada por princípios individualistas.

Existem parentes que fazem parte de um grupo de convivência, que moram em um mesmo terreno e mantêm relações bastante estreitas entre si. A vida de cada família, seus problemas, dificuldades, doenças, bem como as comemorações e festas diversas, passam a ser parte dos demais núcleos domésticos. Forma-se, assim, uma espécie de família extensa, como ocorre com três unidades domésticas, agregadas em torno da figura da mãe.

As intensas relações entre parentes e vizinhos é favorável à troca de favores, que inclui desde simples ajuda em serviços diversos, como cuidar de crianças pequenas e de idosos; executar tarefas domésticas; auxiliar na construção da moradia; realizar empréstimo de dinheiro, alimento, equipamentos domésticos e prestar amparo emocional em casos de doenças e morte. As falas de duas esposas que não exercem trabalho extradoméstico e cujos filhos são pequenos e dependentes de cuidados de adultos, documentam a Paidéia, FFCLRP-USP, Rib. Preto, junho/99. 
necessidade dessas trocas:

O meu cunhado é que comprou uma caixa de leite pro meu filho. Porque o meu marido tá desempregado, ele comprou e deu pra mim. A minha sogra também me ajuda muito, cuida dos meus filhos.

A vizinha de cima já ajuda muito a gente aqui no lote. Quando alguém adoece, ela dá remédio, que às vezes a gente não tem.

Além da doação de bens diversos, as famílias encontram nos parentes e vizinhos amparo de ordem afetiva, com quem compartilham problemas cotidianos. No entanto, apoio e solidariedade têm sua contrapartida em situações negativas, quando a excessiva proximidade e intimidade acarretam invasão da privacidade, redundando em tensões, conflitos e disputas que podem culminar em inimizades, como relata uma esposa:

As outras familias do lote tem vez que interfere na nossa vida e eu não aceito, não. Porque ele (marido) tá errado e eles fica do lado dele. Aí eu falo assim mesmo... este tempo aí atrás, se eu tivesse dinheiro, eu tinha ido embora... porque, nossa, é ruim demais. Ele (marido) quando tava trabalhando eu falei pra ele: "arruma uma casa pra nóis, pelo menos um cômodo".

A fala acima transcrita, de uma mulher que reside em uma casa no terreno onde também se localizam a moradia da sogra e a do cunhado, expressa o desejo de privacidade e autonomia, que se manifesta de modo mais intenso em situações de crise.

Outra fonte de conflito relacionada à defesa da privacidade, ocorre quando um homem se casa e continua morando na residência dos pais e depende destes para manter esposa e filhos, não conseguindo adequar-se à ética de provedor, como também documenta estudo realizado por Agier (1990). Nesse caso, dois homens - pai e filho - podem pretender assumir a chefia familiar em uma mesma moradia, o que é fonte de tensões e desavenças, como acontece em duas das famílias entrevistadas. Quanto às mulheres, a disputa pelo controle doméstico entre sogra e nora, ou entre a esposa e as parentes consangüíneas do marido, geralmente irmãs, também ocasiona problemas na convivência, como ocorre em três famílias. A fala de um marido expressa essa situação:

\section{Eu tenho umas irmãs que mora aí, que mora ai, ela dava palpite, se metia muito na nossa vida, né? Então Deus abençoou de nóis comprá a nossa casa aqui.}

No depoimento acima, encontramos, da perspectiva masculina, a associação entre privacidade e autonomia doméstica vinculada à posse da casa própria e a certo distanciamento dos parentes.

Por sua vez, essa proximidade leva as crianças a não terem noção de delimitação entre a sua casa e a dos parentes e vizinhos, nas quais têm liberdade de fazer refeições, brincar, passar o dia, como relata uma mãe:

Sempre que alguma criança do vizinho aí, se ele chega em casa e a gente tá almoçando, eles almoça também. Então, chega uma criança aqui em casa, é o mesmo que os meus filhos, os meninos do vizinho come também.

As críticas à intromissão de parentes e vizinhos e os problemas daí decorrentes não invalidam a importância que eles têm para essas famílias. De fato, as críticas são antes dirigidas ao que é considerado excesso de participação na vida doméstica, do que a essa participação e aos favores prestados que são essenciais para a reprodução social das famílias.

\section{Considerações finais}

A pesquisa de campo permitiu verificar a diversidade de estratégias de sobreviência das famílias de migrantes dos dois bairros estudados, como a construção de moradia no mesmo terreno onde residem parentes, a troca de bens e serviços com 
parentes e vizinhos que constituem recursos básicos para enfrentar a precariedade do cotidiano, caracterizado pela pobreza, por baixos salários e pelo desemprego.

Como parte dos dados foi coletada na entressafra, alguns trabalhadores estavam desempregados e realizando bicos na construção civil, na limpeza de quintais, na capina das lavouras. Nessas circunstâncias, a sobrevivência da família fica a cargo das mulheres, cuja atividade como empregada doméstica e faxineira é menos afetada pela redução de emprego na lavoura.

No entanto, as esposas tendem a reduzir a importância de sua contribuição para o consumo e a desvalorizar o trabalho doméstico, ao qual não atribuem, como seus maridos também o fazem, a mesma importância de que são revestidas as atividades remuneradas. Entretanto, a produção de valores de uso, bem como a articulação feita pelas esposas com a rede de parentes e com vizinhos é fundamental como estratégia para a reprodução da família e para minimizar situações de conflito e tensão entre marido e esposa.

As formas de solidariedade com parentes e vizinhos convivem com a irrupção de conflitos que, se em alguns casos podem desencadear a ruptura da relação, não eliminam o vínculo entre as famílias, como pode ser documentado pela manutenção da solidariedade que supera os conflitos.

$\mathrm{Na}$ avaliação que essas famílias fazem da migração, há uma apreciação negativa, e bastante objetiva, quando consideram as dificuldades de emprego e os baixos salários. A precariedade das relações de trabalho que obriga os integrantes dessas famílias, em particular os homens, a enfrentarem o desemprego na época da entressafra e a procurarem bicos no setor informal, é uma tônica em todos os depoimentos. Todavia, quando comparam as condições atuais com as do meio rural, expressam uma visão positiva da realidade urbana que também decorre de uma avaliação objetiva da situação em que vivem.

Essa percepção oscilante só pode ser devidamente compreendida quando se considera a possibilidade de acesso a serviços públicos oferecidos pelo Estado que, embora precários e cada vez mais deficientes, inexistiam no local de origem dos migrantes. É dessa perspectiva comparativa que apontam as vantagens da cidade, representadas pelo acesso a esses serviços públicos, dentre os quais destacam o atendimento médico-hospitalar, sobretudo aquele prestado pelo Hospital das Clínicas de Ribeirão Preto, distante 30 quilômetros de Sertãozinho e, acima de tudo, a oportunidade de os filhos frequientarem estabelecimentos de ensino. De fato, todos os entrevistados declaram que a baixa escolaridade os exclui dos melhores empregos, e insistem na imensa importância da escolarização para que os filhos não reproduzam sua história escolar e profissional. A escola é percebida, inclusive, como instituição democrática, formalmente aberta a todos, o que os coloca em igualdade de condições com outros trabalhadores, portanto, como cidadãos. Mesmo que a escolarização seja uma virtualidade e possa não se concretizar, a esperança de que os filhos conquistem o que eles não conseguiram, confere a esses trabalhadores a sensação de dignidade e de poderem exercer a cidadania, pois têm acesso a alguns direitos sociais ainda assegurados pelo Estado.

\section{Referências Bibliográficas}

Abreu Filho, O. de. (1982) Parentesco e identidade social. In: OLIVEIRA, R.C. de. (org) Anuário antropológico 80. Fortaleza: Univ.Fed.do Ceará; Rio de Janeiro: Tempo Brasileiro

Agier, M. (1990) O sexo da pobreza. Homens, mulheres e famílias numa "avenida" em Salvador da Bahia. Tempo Social, v.2, n.2, p. 35-60

Bilac, E. D. (1978) Familias de trabalhadores: estratégias de sobrevivência. São Paulo: Símbolo

Déchaux, J-H. (1990) Les échanges économiques au sein de la parenté. Sociologie du travail, n. 1, p. 73-93

Durham, E. R.(1973) A caminho da cidade: A vida rural e a migração para São Paulo. São Paulo: Perspectiva/EDUSP

Durham, E. R. (1980) A família operária: consciência e ideologia. Dados. Revista de Ciências Sociais, 23(2), p. 201-213

Durham, E. R. (1983) Família e reprodução humana. In: DURHAM, E. R. et alii. Perspectivas antro- 
pológicas da mulher 3. Rio de Janeiro: Zahar

Fausto-Neto, A. M. Q. (1982) Família operária e reprodução da força de trabalho. Petrópolis: Vozes

Fonseca, C. (1987) Aliados e rivais na família: o conflito entre consanguíneos e afins em uma vila porto-alegrense. Revista Brasileira de Ciências. Sociais. 2(4), p. 88-104

Lévi-Strauss, C. (1966) A família. In: SHAPIRO H.L. (org.) Homem cultura e sociedade. Rio de Janeiro: Fundo de Cultura

Macedo, C. C. (1979) A reprodução da desigualdade. São Paulo: Hucitec

Mcmahon, A.(1993) Male readings of feminist theory: the psychologization of sexual politics in the masculinity literature. Theory and society.v. $22 / 4$, p. $675-95$

Montali, L. (1990) Arranjos familiares: o esforço coletivo para viver na Grande São Paulo. Cadernos de pesquisa. $\mathbf{n} .72$, fev.

Oliveira, M.C. (1996) A família no limiar do ano 2000. Estudos feministas, v. 4, n. 1, p. 55-63.

Pitrou, A.(1992) Solidarité publique, solidarité privée. In: SINGLY, F. (org.) La famille. L'état des savoirs. Paris: Éditions La Découverte

Romanelli, G. (1986) Famílias de camadas médias. A trajetória da modernidade. Tese de doutorado, FFLCH/USP, São Paulo (mimeo)

Romanelli, G. (1995) Autoridade e poder na família. In: CARVALHO, M. do C. C. B. de (org.) $A$ família contemporânea em debate. São Paulo: EDUC/CORTEZ

Romanelli, G.(1997) Famílias de classes populares: socialização e identidade masculina. Cadernos de Pesquisa-NEP, N. 1 e 2, p. 25-34

Salem, T. (1989) O casal igualitário. Revista Brasileira de Ciências Sociais. v.3, n. 9, fev. p. 24-37

Schwartz, O. (1990) Le monde privé des ouvriers. Hommes et femmes du Nord. Paris: PUF

Vaitsman, J. (1994) Flexiveis e plurais. Rio de Janeiro: Rocco

Velho, G. (1986) Subjetividade e sociedade. Uma

Paidéia, FFCLRP-USP, Rib. Preto, junho/99. experiência de geração. Rio de Janeiro: Jorge Zahar

Zaluar, A. A máquina e a revolta. São Paulo: Brasiliense, 1985 